\title{
Nasal, eye, and skin irritation in dockyard painters
}

\author{
R Chen, S Semple, F Dick, A Seaton
}

\begin{abstract}
Objectives-To determine whether the risk of irritant symptoms in painters is related to their exposure to paint.

Methods-The prevalences of skin, eye and nasal symptoms were compared in 260 United Kingdom and 109 Chinese dockyard painters, 539 British community controls, and 255 Chinese dockyard controls, relative to their exposure to paints.

Results-Painters showed an excess of irritant symptoms compared with controls. Adjusted relative risks (RRs) $(95 \%$ confidence interval $(95 \% \mathrm{CI})$ were: for skin irritation 1.58 (1.19 to 2.08) in British painters and 2.68 (1.73 to 4.09) in Chinese painters; for eye irritation, 1.41 (0.98 to 2.05 ) and 3.01 (1.90 to 4.76$)$; and for nasal irritation, 1.53 (1.10 to 2.14 ) and 6.73 (3.53 to 12.82), respectively. Exposure durationresponse relations were found for these symptoms; the risks decreased with time after exposure ended.

Conclusions-Irritant symptoms occur more often in dockyard painters than in controls, and this is likely to be a response to exposure to paint.

(Occup Environ Med 2001;58:542-543)
\end{abstract}

Keywords: paint exposures; dockyard painting; health effect; irritant symptoms

Many studies have investigated the health of painters, especially for neuropsychological disorders. ${ }^{1-4}$ Some papers have reported an excess of irritant symptoms. ${ }^{56}$ In two studies investigating relations between painting and neuropsychological symptoms we had included questions on skin, eyes, and nasal irritation, ${ }^{23}$ and now report our analysis of the responses.

\section{Subjects and methods}

The design, described in previous publications, ${ }^{23}$ was a cross sectional study of both active and retired men from a cohort of dockyard painters in Scotland, with community controls, duplicated by a study of dockyard painters and controls in China. In Scotland 260 dockyard painters and 539 community controls completed the questionnaires. There was a practical response rate of $49 \%$ for painters and $62 \%$ for controls. In China, the subjects were 116 dockyard painters (66 men) and 263 non-painters (188 men). Of the painters $94 \%$ and of the controls $97 \%$ completed the questionnaires. Response bias was avoided by avoiding mention of a specific interest in paints
Main messages

- Dockyard painters were more likely than controls to report irritant symptoms of eyes, skin, and nose.

- Likelihood of symptoms increased with duration of exposure to paint and reduced after exposure ended.

- Duration of exposure correlated well with more detailed exposure estimates in the heavily exposed workers.

or solvents. The similarity of the results in the two studies allowed us to argue that the relatively low response rate in the United Kingdom study had not introduced bias. ${ }^{3}$

The questionnaire has been described previously. ${ }^{2}$ The questions on irritant symptoms were: "Do you often get itching of your skin?", "Do your eyes often get red or inflamed?" and "Do you often have a runny nose?" These were translated into Chinese for the Chinese study. Duration of employment as a dockyard painter was used as a surrogate for exposure, and the validity of this was assessed by comparison with the results of a detailed assessment of cumulative exposure to solvents ${ }^{7}$ in a subgroup of 82 of the subjects. British and Chinese data were analysed separately. Relative risks (RRs) for British and Chinese painters who had each of the three irritant symptoms or two of the three symptoms with adjustment for age, educational level, smoking, alcohol intake, and social conformity (on the Eysenck L scale), were calculated and compared with controls by a Breslow-Cox regression model. In a multivariate case-control analysis of irritant symptoms, a logistic regression model was used to estimate the magnitude of effects of exposure to painting, and odds ratios (ORs) were computed, where continuous variables were divided into quartiles for British data and tertiles for Chinese data. In the United Kingdom data we examined whether the risk of symptoms decreased with time elapsed since the end of exposure. Pearson correlation analysis was used

\section{Policy implications}

- Minor, but sometimes important, symptoms occur commonly in painters and may indicate excessive exposure. Together with previous reports from this study, the present analysis adds weight to the need for a review of occupational exposure standards for paint solvents. 
Table 1 Relative risks of irritant symptoms in dockyard painters

\begin{tabular}{|c|c|c|c|c|c|c|c|c|c|c|c|c|}
\hline \multirow[b]{2}{*}{ Symptoms } & \multicolumn{6}{|c|}{ United Kingdom } & \multicolumn{6}{|l|}{ China } \\
\hline & $\begin{array}{l}\text { Painters } \\
n=260\end{array}$ & $R R$ & $95 \% C I$ & $\begin{array}{l}\text { Controls } \\
n=539\end{array}$ & $R R^{\star}$ & $95 \% C I$ & $\begin{array}{l}\text { Painters } \\
n=109\end{array}$ & $R R$ & $95 \% C I$ & $\begin{array}{l}\text { Controls } \\
n=255\end{array}$ & $R R+$ & $95 \% C I$ \\
\hline Skin & 109 & 1.48 & 1.21 to 1.80 & 153 & 1.58 & 1.19 to 2.08 & 55 & 2.73 & 1.99 to 3.76 & 47 & 2.68 & 1.73 to 4.09 \\
\hline Eyes & 61 & 1.35 & 1.01 to 1.79 & 94 & 1.41 & 0.98 to 2.05 & 44 & 2.57 & 1.79 to 3.71 & 40 & 3.01 & 1.90 to 4.76 \\
\hline Nose & 80 & 1.55 & 1.21 to 1.99 & 107 & 1.53 & 1.10 to 2.14 & 41 & 6.85 & 3.90 to 12.04 & 14 & 6.73 & 3.53 to 12.82 \\
\hline Total with two & 78 & 1.84 & 1.41 to 2.40 & 88 & 1.86 & 1.31 to 2.63 & 44 & 4.48 & 2.85 to 7.03 & 23 & 4.99 & 2.92 to 8.54 \\
\hline
\end{tabular}

*Adjusted for age, educational level, smoking, alcohol intake, and social conformity, additionally sex for Chinese data.

to test the relations between years of employment as a dockyard painter and detailed estimates of exposure to solvents.

\section{Results}

Both British and Chinese dockyard painters had an excess of irritant symptoms of the skin, eyes, and nose: adjusted RRs for British painters were around 1.50, whereas those for Chinese painters were over 2.50 (table 1). Within the Chinese data, there was no significant difference between sexes. Duration of employment proved to be an adequate surrogate for exposure to solvents, the Pearson correlation coefficient for duration against estimates of detailed exposure to solvents in a subgroup of 82 subjects being $0.82(\mathrm{p}<0.01)$.

In a case-control analysis, comparing those with symptoms to those without, crude ORs (95\% confidence interval (95\% CI)) for British painters with irritant symptoms from skin, eyes, or nose were 1.82 (1.34 to 2.48 ), 1.45 (1.01 to 2.09 ), and 1.79 (1.28 to 2.52 ); for Chinese painters the corresponding figures were 4.51 (2.76 to 7.37 ), 3.64 (2.18 to 6.06 ), and 10.38 (5.35 to 20.16), respectively. Exposure-response relations were found both in British and Chinese painters, and examined in a multivariate analysis. Compared with unexposed people, the OR for British painters with two out of three irritant symptoms was 1.81 (0.98 to 3.36) for 1-3 years of exposure, 2.19 (1.19 to 4.04 ) for $4-7$ years, 2.06 (1.12 to 3.78 ) for $8-14$ years and 2.39 (1.28 to 4.46$)$ for 15-41 years. In Chinese painters the ORs (95\% CIs) were 5.83 (2.53 to 13.46 ) for $2-17$ years of exposure and 10.78 (4.94 to 23.53) for 18-43 years. In the multivariate logistic regression models, the ORs for age, educational level, smoking, alcohol, and social conformity were not significant, but the Chinese men had a higher risk than women.

Among the British painters, the relative risks of symptoms tended to decrease with time after the end of exposure. Adjusted for confounders, the RRs at 1-6 years after the end of exposure to painting, compared with those still at work, were $0.90(0.53$ to 1.52$)$ for itchy skin, 0.89 ( 0.46 to 1.73 ) for sore eyes, 0.63 (0.33 to 1.21 ) for runny nose, and 0.61 (0.32 to 1.14) for two of three symptoms. At 7-13 years after leaving exposure to painting the corresponding figures were 0.72 (0.41 to 1.28$), 0.48$ (0.22 to 1.08$)$, 0.75 (0.40 to 1.41 ), and 0.54 (0.28 to 1.07$)$.

\section{Discussion}

Most of the painters in the United Kingdom had heavy exposure in confined spaces, both through the respiratory tract and the skin. ${ }^{8}$ It is likely that the Chinese painters had similar exposures. Although exposure was estimated by years of employment, our detailed exposure assessment showed that duration in this trade was highly correlated with lifetime cumulative exposure to solvents. The association between exposure and irritant symptoms is consistent with previous studies. ${ }^{5910}$ Wieslander et al found the OR for painters with itching hands to be 1.9 (1.1 to 3.3), although the risks for symptoms from irritant cough and blocked nose were not significantly increased. ${ }^{9}$ Swedish house painters have also been shown to have an increased risk of eye irritation. ${ }^{9}$ White and Baker found increasing prevalence of transient eye irritation with increasing number of weeks worked with solvents. ${ }^{5}$

The study has shown that all three irritant symptoms were significantly related to exposure to paint, but had a tendency to resolve after stopping exposure to painting. This and our other studies have shown painters to be at increased risk of several physical and neuropsychological symptoms. These are often minor, are commonly present in the general population, and therefore easily dismissed as unimportant or accepted as "part of the job". They may, however, sometimes be more serious and even disabling and contribute to putting these manual workers at further social and physical disadvantage.

RC was supported by the Colt Foundation and a grant from The Royal Society. SS is supported by a grant from the United Kingdom Health and Safety Executive.

1 International Agency for Research on Cancer. Some organic solvents, resin monomers and related compounds, pigments and occupational exposures in paint manufacture and painting. occupational exposures in paint manufacture and
Lyon, France: IARC, 1989. (Monograph 47.)

2 Chen R, Dick F, Seaton A. Health effects of solvent exposure among dockyard painters: mortality and neuropsychological symptoms. Occup Environ Med 1999;56:3837.

3 Chen R, Wei L, Seaton A. Neuropsychological symptoms in Chinese male and female painters: an epidemiological study in dockyard workers. Occup Environ Med 1999;56: $388-90$

4 Baker EL. A review of recent research on health effects of human occupational exposure to organic solvents. $\mathcal{F}$ Occup Med 1994;36:1079-92.

5 White MC, Baker EL. Measurements of respiratory illness among construction painters. Br F Ind Med 1988;45:52331.

6 Winchester RV, Madjar VM. Solvent effects on workers in the paint, adhesive and printing industries. Ann Occup Hyg 986;30:307-17.

7 Semple S, Dick F, Osborne A, et al. Impairment of colour vision in workers exposed to organic solvents. Occup Environ Med 2000;57:582-7.

8 Dick F, Semple S, Chen R, et al. Neurological deficits in solvent-exposed painters: a syndrome including impaired colour vision, cognitive defects, tremor and loss of vibration sensation. Qf Med 2000;93:655-61.

9 Wieslander G, Norback D, Edling C. Occupational exposure to water-based paint and symptoms from the skin and eyes. Occup Environ Med 1994;51:181-6.

10 Hempel-Jorgensen A, Hudnell $\mathrm{KH}$. Sensory eye irritation in humans exposed to mixtures of volatile organic compounds. Arch Environ Health 1999;54:416-24. 